\title{
Correction to: Tracheal intubation in critically ill patients: a comprehensive systematic review of randomized trials
}

Luca Cabrini ${ }^{1,2}$, Giovanni Landoni ${ }^{1,2}$, Martina Baiardo Redaelli , Omar Saleh', Carmine D. Votta', Evgeny Fominskiy ${ }^{1,3}$, Alessandro Putzu ${ }^{4}$, Cézar Daniel Snak de Souza ${ }^{5}$, Massimo Antonelli, Rinaldo Bellomo ${ }^{7,8}$, Paolo Pelosi ${ }^{9^{*}}$ and Alberto Zangrillo ${ }^{1,2}$

\section{Correction to: Crit Care (2018) 22:6 https://doi.org/10.1186/s13054-017-1927-3}

In the publication of this article [1], there was an error in a contributors Family Name. This has now been updated in the original article.

The error: Baiardo Radaelli

Should instead read: Baiardo Redaelli

\begin{abstract}
Author details
'Department of Anaesthesia and Intensive Care, IRCCS San Raffaele Scientific Institute, Via Olgettina 60, 20132 Milan, Italy. ${ }^{2}$ Università Vita-Salute San Raffaele, Via Olgettina 58, 20132 Milan, Italy. ${ }^{3}$ Department of Anesthesia and Intensive Care, Siberian Biomedical Research Center of the Ministry of Health, Novosibirsk, Russia. ${ }^{4}$ Department of Cardiovascular Anesthesia and Intensive Care, Cardiocentro Ticino, Lugano, Switzerland. ${ }^{5}$ Department of Surgery, Discipline of Anesthesiology, Critical Care and Pain Medicine, Federal University of São Paulo, São Paulo, Brazil. ${ }^{6}$ Department of Intensive Care Medicine and Anaesthesiology, Fondazione Policlinico Universitario A. Gemelli, Università Cattolica del Sacro Cuore, Rome, Italy. ${ }^{7}$ Department of Intensive Care, Austin Hospital, Heidelberg, Australia. ${ }^{8}$ School of Medicine, The University of Melbourne, Melbourne, Australia. ${ }^{9}$ Department of Surgical Sciences and Integrated Diagnostics, San Martino Policlinico Hospital, IRCCS for Oncology, University of Genoa, Largo Rosanna Benzi 8, 16131 Genoa, Italy.
\end{abstract}

Published online: 21 October 2019

\section{Reference}

1. Cabrini L, Landoni G, Baiardo Redaelli M, et al. Tracheal intubation in critically ill patients: a comprehensive systematic review of randomized trials. Crit Care. 2018;22:6. https://doi.org/10.1186/s13054-017-1927-3.

\footnotetext{
* Correspondence: ppelosi@hotmail.com

${ }^{9}$ Department of Surgical Sciences and Integrated Diagnostics, San Martino Policlinico Hospital, IRCCS for Oncology, University of Genoa, Largo Rosanna Benzi 8, 16131 Genoa, Italy

Full list of author information is available at the end of the article
}

(c) The Author(s). 2019 Open Access This article is distributed under the terms of the Creative Commons Attribution 4.0 International License (http://creativecommons.org/licenses/by/4.0/), which permits unrestricted use, distribution, and reproduction in any medium, provided you give appropriate credit to the original author(s) and the source, provide a link to the Creative Commons license, and indicate if changes were made. The Creative Commons Public Domain Dedication waiver (http://creativecommons.org/publicdomain/zero/1.0/) applies to the data made available in this article, unless otherwise stated. 